\title{
Critical thinking and accuracy of nurses' diagnoses. Part II: application of cognitive skills and guidelines for self-development*
}

\author{
PENSAMENTO CRÍTICO E ACURÁCIA DOS DIAGNÓSTICOS DE ENFERMAGEM. PARTE II: \\ APLICAÇÃO DE HABILIDADES COGNITIVAS E GUIA PARA O AUTO-DESENVOLVIMENTO \\ PENSAMIENTO CRÍTICO Y PRECISIÓN DE LOS DIAGNÓSTICOS DE ENFERMERÍA. II PARTE: \\ APLICACIÓN DE HABILIDADES COGNITIVAS Y GUIA PARA ELAUTODESARROLLO.
}

\section{Margaret Lunney ${ }^{1}$}

\section{RESUMO}

Na Parte I deste artigo, $o$ autor explicou as dificuldades em alcançar a acurácia dos diagnósticos de enfermagem, a relevância do pensamento crítico no alcance dessa acurácia e as mais novas perspectivas desse pensamento. Na Parte II, as dimensões do pensamento crítico identificadas como importantes para a prática de enfermagem são aplicadas em um estudo de caso de uma menina de 16 anos com Diabetes do tipo 1. A aplicação das sete habilidades cognitivas e das dez formas de pensar ilustram a importância do uso do pensamento crítico para a acurácia dos diagnósticos de enfermagem. Dez estratégias são propostas para o autodesenvolvimento de habilidades para o pensamento crítico.

\section{PALAVRAS-CHAVE}

Pensamento crítico. Diagnóstico de Enfermagem. Acurácia.

\begin{abstract}
Part I of this article, the author explained the difficulties of achieving accuracy of nurses', diagnoses, the relevance of critical thinking to the achievement of accuracy, and newer views of critical thinking. In Part II, the critical thinking dimensions identified as important for nursing practice are applied in the diagnostic process using a case study of a 16 year old girl with type 1 diabetes.

Application of seven cognitive skills and ten habits of mind illustrate the importance of using critical thinking for accuracy of nurses' diagnoses. Ten strategies are proposed for self-development of critical thinking abilities.
\end{abstract}

\section{KEYWORDS}

Critical Thinking.

Nursing Diagnosis.

Accuracy.

\section{RESUMEN}

En la I Parte del artículo, el autor explicó las dificultades para alcanzar la precisión de los diagnósticos de enfermería, la relevancia del pensamiento crítico en el logro de esa precisión y las nuevas perspectivas de ese pensamiento. En la II Parte las dimensiones del pensamiento crítico, consideradas como importantes para la práctica de enfermería, son aplicadas en el estudio de caso de una joven de 16 años con Diabetes de tipo 1. La aplicación de las siete habilidades cognitivas y de las diez formas de pensar, ilustra la importancia del uso del pensamiento crítico para la precisión de los diagnósticos de enfermería. Se proponen diez estratégias para el autodesarrollo de habilidades volcadas al pensamiento crítico.

\section{PALABRAS-CLAVE}

Pensamiento crítico. Diagnóstico de enfermería. Precisión.

\author{
* This article was adapted \\ from a course \\ presented in March \\ 2003 at the University \\ of Sao Paulo. \\ 1 Professor Department \\ of Nursing College \\ of Staten Island, \\ The City University \\ of New York (CUNY). \\ lunney@postbox.csi.cuny.edu
}

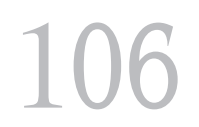

Rev Esc Enferm USP 2003; 37(3): 106-12. 
In part I of this paper, the importance of accuracy of nurses' diagnoses, the risk of low accuracy diagnoses, the relationship of critical thinking to accuracy, and newer views of critical thinking were explained. Research findings from a study by Scheffer and Rubenfeld (1), which identified seven cognitive skills and ten habits of mind that are essential for nursing practice, were presented (see Table 1).
Critical thinking and accuracy of nurses' diagnoses. Part II: application of cognitive skills and guidelines for self-development

Table 1 Critical Thinking In Nursing*

\begin{tabular}{|c|c|}
\hline Dimensions & Definitions \\
\hline Cognitive Skills & Separating or breaking a whole into parts to discover the \\
\hline $\begin{array}{l}\text { Analyzing } \\
\text { Applying Standards }\end{array}$ & $\begin{array}{l}\text { Judging according to established personal, professional, or } \\
\text { social rules or criteria }\end{array}$ \\
\hline Discriminating & $\begin{array}{l}\text { Recognizing differences and similarities among things or } \\
\text { situations and distinguishing carefully as to category or } \\
\text { rank }\end{array}$ \\
\hline Information Seeking & $\begin{array}{l}\text { Searching for evidence, facts or knowledge by identifying } \\
\text { relevant sources and gathering objective, subjective, } \\
\text { historical and current data from those sources. }\end{array}$ \\
\hline Logical Reasoning & $\begin{array}{l}\text { Drawing inferences or conclusions that are supported in or } \\
\text { justified by evidence }\end{array}$ \\
\hline Predicting & Envisioning a plan and its consequences \\
\hline Transforming knowledge & $\begin{array}{l}\text { Changing or converting the condition nature, form or } \\
\text { function of concepts among contexts }\end{array}$ \\
\hline Habits of Mind & \\
\hline Confidence & Assurance of one's reasoning abilities. \\
\hline Contextual perspective & $\begin{array}{l}\text { Consideration of the whole situation, including } \\
\text { relationships, background, and environment, relevant to } \\
\text { some happening. }\end{array}$ \\
\hline Creativity & $\begin{array}{l}\text { Intellectual inventiveness used to generate, discover, or } \\
\text { restructure ideas; imagining alternatives. }\end{array}$ \\
\hline Flexibility & $\begin{array}{l}\text { Capacity to adapt, accommodate, modify or change } \\
\text { thoughts, ideas and behaviors }\end{array}$ \\
\hline Inquisitiveness & $\begin{array}{l}\text { An eagerness to know by seeking knowledge and } \\
\text { understanding through observation and thoughtful } \\
\text { questioning in order to explore possibilities and } \\
\text { alternatives. }\end{array}$ \\
\hline Intellectual integrity & $\begin{array}{l}\text { Seeking the truth through sincere, honest processes, even if } \\
\text { the results are contrary to one's assumptions and beliefs. } \\
\text { Insightful sense of knowing without conscious use of reason. } \\
\text { A viewpoint characterized by being receptive to divergent } \\
\text { views and sensitive to one's biases. }\end{array}$ \\
\hline Open-mindedness & $\begin{array}{l}\text { Pursuit of a course with determination to overcome } \\
\text { obstacles }\end{array}$ \\
\hline Perseverance & $\begin{array}{l}\text { Contemplation upon a subject, especially one's } \\
\text { assumptions and thinking for purposes of deeper }\end{array}$ \\
\hline Reflection & understanding and self-evaluation. \\
\hline
\end{tabular}

* Scheffer BK, Rubenfeld GM. A consensus statement on critical thinking in nursing. J Nurs Educ 2000; 39(8): 352-359.

The purposes of Part II are to apply the seven cognitive skills with the case study of $\mathrm{MH}$ (see Table 2), show the relevance of some of the ten habits of mind to the cognitive skills, and describe ten strategies for selfdevelopment of critical thinking abilities. 
(1) $\mathrm{MH}$ is a 16 year old female who has had type 1 diabetes for 10 years. (2) She was admitted 3 days ago for treatment of an acute episode of diabetic ketoacidosis. (3) When Marian discussed with you how she managed the therapeutic regimen before hospitalization, she states that she was not adhering to her prescribed diet. (4) As Marian's nurse, you decide that Marian needs assistance to improve her management of the therapeutic regimen, especially the types of foods that she eats. (5) Marian's stay in the hospital unit is uneventful, in that medical treatments are successfully resolving the crisis.

(6) Marian's daily habits include getting up for school about 7 a.m. and rushing to get the bus by 7:30. (7) She says, she should get up about 6:30 but she likes to sleep. (8) She states that she does not want her mother to help her to get up earlier. (9) The meal she eats at school is consistent with her prescribed diet, while the two meals at home are not. (10) In the morning, she grabs whatever is quick and easy, usually toast and butter. (11) In the evening, her mother makes meals that comply with the diabetic diet but Marian states that she does not like them so she only eats part of her supper and then snacks on other foods later.

(12) Marian is able to explain to you what she should be eating and that she can adjust her diet to her lifestyle. (13)The knowledge of what foods are on her diet that she likes was not discussed with her mother because she did not want to sit down and talk with her. (14) In general, Marian and her mother argue over many of Marian's behaviors, such as school grades, smoking, and coming in late at night.

Nursing Diagnosis: Ineffective management of therapeutic regimen related to

\section{Use of the Seven Cognitive Skills in Selecting a Diagnosis with $\mathrm{MH}$}

The seven cognitive skills (Table 1) are applied to the case study of MH (Table 2) in alphabetical order, not necessarily in the order in which they would be used or in order of importance. It is assumed that the ten habits of mind support the development and use of these cognitive skills. Selected examples of the habits of mind are included with each cognitive skill.

\section{Cognitive Skill: Analyzing}

In the diagnostic process, analyzing involves breaking the situation into parts in order to consider possible meanings. With $\mathrm{MH}$, the cognitive skill of Analyzing is used when the meanings of specific data, sentences, and/or paragraphs are considered and when the relevance of specific cues are considered in relation to possible diagnoses. In the first paragraph, for example, the nurse may decide that sentence number three has high relevance for making the diagnosis, Ineffective Management of Therapeutic Regimen, especially regarding her diabetic diet. A commonly considered etiology for this nursing diagnosis is knowledge deficit, but in sentences 9 and 12, MH states that she knows what she is supposed to eat. Flexibility, a habit of mind, influences the process of analyzing because mental flexibility enables nurses to consider other, less obvious, explanations besides knowledge deficit.

\section{Cognitive Skill: Applying Standards}

With the cognitive skill of Applying Standards, the nurse selects standard(s) that fit the situation, considers how to apply the standards, and tests the applicability of specific standards. Examples of standards that should be applied with $\mathrm{MH}$ are the types of knowledge needed by people with diabetes to effectively manage their therapeutic regimens, factors that impact on the likelihood of people taking action to protect their health, e.g., factors identified in the health belief and health promotion models ${ }^{(2)}$, effective communication techniques for use with teenagers, developmental tasks and needs, the research-based defining characteristics of nursing diagnoses see NANDA International ${ }^{(3)}$, standards set by the hospital system, and others. The habits of mind Inquisitiveness and 
Intellectual Integrity influence the application of standards by prompting nurses to seek additional standards as indicated by the clinical situation and to use standards even when it requires a sacrifice of time, and effort.

\section{Cognitive Skill: Discriminating}

Discriminating involves consideration of how a situation is similar to, or different than, other situations, and evaluation of the relevance of cues to each of the possible diagnoses. For MH, the mother-daughter relationship is similar to other teenage girls and their mothers but it differs in that the effects of poor mother-daughter communication on MH's disease status are more serious and need to be addressed at once. With data in this case study, the nurse can discriminate that the cues for communication difficulties between mother and daughter (sentence numbers 8, 9,11 and 13) are strong enough to decide that this is the primary etiology for the diagnosis of Ineffective Management of Therapeutic Regimen. Selecting the most accurate etiology is important because it guides interventions for the diagnosis. The habits of mind Reflection, Flexibility, and Open-Mindedness, affect the cognitive skill of Discriminating by helping the nurse to avoid rote thinking and to reject the most commonly considered diagnoses and etiologies when there are sufficient data to do so.

\section{Cognitive Skill: Information Seeking}

Information seeking is used to consider whether additional information is needed for the diagnostic process, to identify possible sources of information, and to obtain additional information as needed. With MH, the nurse uses Information Seeking to collaborate with $\mathrm{MH}$ and her mother on what is the diagnosis, to consider whether collaboration is also needed with another health care provider (e.g., a specialist in diabetes), to read about the concept of management of therapeutic regimen and its contributing factors, to conduct a more indepth health history, to study about teenage development, and so forth. Contextual Perspective will be used by the nurse to consider the difficulties that probably exist between mothers and daughters who have been involved in management of the daughter's therapeutic regimen over long periods of time and during teenage development. Intuition might influence information seeking when the nurse perceives a subtle tension between mother and daughter.

\section{Cognitive Skill: Logical Reasoning}

With Logical Reasoning, the nurse examines the relevance of data to cluster cues in meaningful patterns, and compare possible diagnostic explanations with specific cues or cue clusters. With $\mathrm{MH}$, the etiology of teenage development would be judged as being relevant to explaining MH's behavior but it is not useful as a nursing diagnosis because it is not amenable to nursing intervention. The data or cues for mother-daughter conflict is close to the best interpretation but is not as precise as Communication Difficulties between Mother and Daughter. Flexibility, as a habit of mind, is critically important for logical reasoning so that a variety of inferences would be considered and the nurse would not just think about the most commonly considered nursing diagnoses, e.g., knowledge deficit.

\section{Cognitive Skill: Predicting}

With Predicting, the nurse considers possible explanations for the data, anticipates implications from both data and inferences, and considers the relationship of diagnoses to nursing interventions. With $\mathrm{MH}$, the nurse predicts that the communication difficulties between $\mathrm{MH}$ and her mother must be addressed for optimum management of the therapeutic regimen and to avoid further diabetic complications. The nurse considers possible interventions for Ineffective Management of Therapeutic Regimen related to Communication Difficulties between Mother and Daughter and realizes that the nursing interventions of Communication Enhancement (Nursing Interventions Classification $\{\mathrm{NIC}\}, 2000)$ and Developmental Enhancement: Adolescent (NIC, 2000) can be used to help $\mathrm{MH}^{(4)}$. Confidence, as habit of mind, is derived from nursing knowledge and experience and provides a basis to use knowledge and experience for Predicting diagnoses to guide an effective plan of care for $\mathrm{MH}$.
Critical thinking and accuracy of nurses' diagnoses. Part II: application of cognitive skills and guidelines for self-development 


\section{Cognitive Skill: Transforming Knowledge}

With Transforming Knowledge, the nurse uses knowledge from past experiences, and adapts knowledge from one type of situation to other types of situations. With $\mathrm{MH}$, the nurse may use personal experiences with teenage family members, professional experiences with older diabetics, and/or professional and personal experiences with caregiver relationships. Knowledge is transformed when it is adapted for other uses. The habits of mind, Creativity, OpenMindedness and Flexibility, support knowledge transformation, by helping nurses to see other ways to use knowledge besides the common and traditional ways.

\section{Development of CT for Accuracy of Nurses' Diagnoses}

Nurses need to continuously develop the cognitive skills and habits of mind of critical thinking because the clinical situations that nurses interpret are complex and diverse, making achievement of accuracy of nurses' diagnoses a challenging task. Development of critical thinking abilities can be accomplished through 10 strategies for selfdevelopment (see Table 3).

Table 3 - 10 Strategies for Self Development of Critical Thinking for Diagnostic Accuracy

1) Think about your thinking (e.g., 7 cognitive skills \& 10 habits of mind)
2) Connect with the thinking of others
3) Identify and challenge assumptions, inferences, and/or interpretations
4) Consider alternative possibilities and use reflective skepticism
5) Balance reflective skepticism with trust in self and others
6) Develop sensitivity to contextual factors
7) Evaluate the credibility of evidence
8) Recognize and accept intuitive knowing
9) Tolerate the ambiguity of clinical judgments
10) Control anxiety about the possibility of being "wrong"

The first strategy is to think about the thinking processes used in the diagnostic process. This involves current (while diagnosing) or retrospective examination of thinking processes. Knowledge of the critical thinking terms identified by Scheffer and Rubenfeld (1) enables nurses to think about and improve these cognitive skills and habits of mind. The cognitive skills and habits of mind can be improved through increased use, e.g., case studies can be used in health care agencies as well as schools of nursing to practice use of critical thinking and focus on identification of the types of thinking being used in the diagnostic process. Teachers can guide students' development of these abilities as shown by Carlson-Catalano ${ }^{(5)}$. Another teaching strategy is to require clinical journals in which students describe their thinking processes during the diagnostic process ${ }^{(6-7)}$.

The second strategy, connect with the thinking of others, creates synergistic combinations of nurses' thinking abilities to produce higher-level abilities ${ }^{(8)}$. This can be accomplished through discussions of the diagnostic process with case study simulations and/or actual clinical cases. Through discussion, nurses learn from each other and observe other ways of thinking about issues.

The third strategy to improve critical thinking abilities is to recognize assumptions, inferences, and/or interpretations so that they can be discussed and/ or challenged. If nurses do not fully realize that inferences are arbitrary meanings assigned to data and, thus, possibly incorrect, they will not be able to address the issue of accuracy. To achieve accuracy, nurses must be able to challenge diagnoses that they believe might be inaccurate. To prompt recognition of inferences, for example, teachers can give students lists of data and ask students to identify the inferences. To stimulate students' abilities to challenge assumptions or inferences, teachers can ask questions of students about possible inferences instead of providing them with the answers. The strategy of teachers asking questions is one of the best ways to promote critical thinking skills of all types. 
The fourth strategy, consider alternative diagnostic possibilities, prompts broadening of the mind during use of cognitive skills and supports development of reflection, mental flexibility, and open-mindedness. Achievement of accuracy may depend on the correct diagnosis being in the original set of diagnoses being considered. If so, the more possible diagnoses that nurses consider, the higher the level of accuracy. Developing a habit of reflective skepticism (Brookfield, 1991) can help nurses decide when alternative diagnostic possibilities should be considered. Teachers can encourage development of this ability by prompting students to name many all possible diagnoses from case studies. Theorists on creative problem solving advocate brainstorming and suspension of evaluation as a way to generate other possibilities ${ }^{(9)}$.

The fifth strategy, balance reflective skepticism with trust in self and others, recognizes that sometimes the diagnostic process involves routine elements that enable quick, efficient, and accurate diagnoses. Developing a balance of reflective skepticism with trust in self and others supports a process of questioning and challenging some diagnoses and accepting other diagnoses as accurate until evidence shows otherwise.

The sixth strategy, develop sensitivity to contextual factors, is needed to help nurses consider the effects of contextual factors, e.g., age, culture, family situations, emotional states, on the possible meanings of data. For example, the contextual factor in this case was that $\mathrm{MH}$ has had type 1 diabetes for ten years. Her mother managed the therapeutic regimen when she was younger and the change from child to adolescent is likely to lead to power conflicts over therapeutic regimen management. When nurses are trying to understand patient situations, questions should always be asked about the relevance of the context to the meaning of the data. Teachers can help students to develop this ability by discussing the diagnostic process with specific cases and how the context of situations affects the meaning of data.

The seventh strategy, evaluate the credibility of evidence, is essential for the achievement of diagnostic accuracy. The evidence associated with specific clinical situations can be compared with the signs and symptoms for nursing diagnoses ${ }^{(3)}$. Group discussions of how well the evidence matches specific diagnoses can be con- ducted. Nurse colleagues and patients can validate that diagnoses match the evidence. Teachers can support use of this strategy by including questions related to the match between evidence and diagnoses on course examinations and generating class discussions of the adequacy of evidence.

The eighth strategy, recognize and accept intuitive knowing, reflects new views of CT. With intuition, nurses act quickly to diagnose and treat human responses without necessarily being able to describe the data that led to diagnostic decisions. Experience with similar situations may give nurses a sense of knowing the meaning of situations before clear data are available to support analysis and logical reasoning.

The ninth strategy, tolerate the ambiguity of clinical judgments, is essential for growth as a diagnostician. Nurses may not be comfortable with ambiguity but tolerance for ambiguity is needed to focus on accuracy. With diagnosing, there is a risk of making mistakes but these risks need to be taken for the benefit of patients. The higher risk associated with naming diagnoses is associated with the higher benefits of making it possible for others to challenge the accuracy of diagnoses and for accurate diagnoses to guide nursing interventions.

The tenth strategy, control anxiety about being "wrong" enables nurses to examine the possibility of low accuracy. Generally, making mistakes can be a threat to a person's self esteem, contributing to feelings of anxiety or fear. These negative feelings can be controlled through positive self-talk and other cognitive strategies. When these feelings occur, nurses can reaffirm the meaning of being a diagnostician. Diagnosticians are always at risk of making mistakes; the goal should be to do the best possible job considering the context of the diagnostic situation and to adapt to the possibility of being "wrong." Nurses need to allow themselves the possibility of making mistakes since it is part of the diagnostic process.

Accuracy of nurses' diagnoses of human responses provides the basis for successful nursing interventions, yet achieving accuracy of nurses' diagnoses is probably much more difficult than was previously recognized. The author proposes that enhancing critical thinking abilities will facilitate improved accuracy.
Critical thinking and accuracy of nurses' diagnoses. Part II: application of cognitive skills and guidelines for self-development 
(1) Scheffer BK, Rubenfeld MG. A consensus statement on critical thinking. J Nur Educ 2000; 39: 352-359.

(2) Pender NJ, Murdaugh CL, Parsons MA. Health promotion in nursing practice $4^{\text {th }}$ ed. Upper Saddle River, NJ: Prentice Hall; 2002.

(3) NANDA International. Nursing diagnoses: Definitions and Classification 2003-2004. Philadelphia: Author; 2003.

(4) McCloskey JC, Bulechek GM. (Eds.). Nursing interventions classification (NIC), Iowa intervention project (3rd ed.). St. Louis: Mosby; 2000.

(5) Carlson-Catalano J. A teaching method for diagnostic skill development. In: Lunney $\mathrm{M}$. Critical thinking and nursing diagnosis: Case studies and analyses. Philadelphia: NANDA International; 2001
(6) Degazon C, Lunney M. Clinical journal: A tool to foster critical thinking for competence in advanced practice. Clin Nurse Spec: 1995; 9 (5): $270-274$

(7) Lunney M. Critical thinking and nursing diagnosis: Case studies and analyses. Philadelphia: NANDA International, 2001.

(8) Hayakawa SI, Hayakawa AR. Language in thought and action (5th ed.). San Diego: Harcourt Brace Company; 1990.

(9) Michalko M. Cracking creativity: The secrets of creative genius. Berkley, CA: Ten Speed Press; 2001.

The author thanks Dra. Dina A. Lopes Monteiro da Cruz for her contributions to course development. 